\title{
PENGARUH SUHU DERAAN DAN LAMA PENDERAAN PADA VIABILITAS BENIH TOMAT (Lycopersicon esculentum Mill.) VARIETAS OVAL
}

\author{
Kristin Stefiana Marbun, Eko Pramono, \& M. Syamsoel Hadi \\ Jurusan Agroteknologi, Fakultas Pertanian Universitas Lampung \\ Jl. Prof. Soemantri Brodjonegoro, No. 1, Bandar Lampung 35145 \\ stefiana_k@yahoo.com
}

\begin{abstract}
ABSTRAK
Penelitian ini dilakukan untuk mengetahui kombinasi perlakuan suhu deraan dan lama penderaan yang efektif menurunkan viabilitas benih tomat. Penelitian ini menggunakan rancangan perlakuan faktorial 2 faktor $(2 \times 6)$ dalam rancangan kelompok teracak sempurna, dengan 3 kali ulangan. Faktor pertama adalah suhu yang terdiri dari 2 taraf, yaitu $39^{\circ} \mathrm{C}$ dan $41^{\circ} \mathrm{C}$. Faktor kedua adalah lama penderaan yang terdiri dari 6 taraf, yaitu 0 jam, 24 jam, 48 jam, 72 jam, 96 jam, dan 120 jam. Data dianalisis dengan analisis ragam dan diuji lanjut menggunakan Uji Beda Nyata Terkecil (BNT) dengan $\alpha=0,05$. Hasil penelitian menunjukkan bahwa interaksi suhu deraan dan lama penderaan dapat menurunkan viabilitas benih tomat ditunjukkan oleh variabel kecambah normal kuat, panjang akar primer, dan bobot kering kecambah normal, dengan kombinasi suhu $39^{\circ} \mathrm{C}$ dengan lama penderaan $24 \mathrm{jam}$ atau suhu $41^{\circ} \mathrm{C}$ dengan lama penderaan $24 \mathrm{jam}$.
\end{abstract}

Kata kunci: benih tomat, lama deraan, suhu, viabilitas

\section{PENDAHULUAN}

Tomat termasuk dalam jenis tanaman sayuran yang sering digunakan sebagai bahan pangan dan industri. Menurut BPS, produksi tomat di Lampung tahun 2011 mencapai18.420 ton ha ${ }^{-1}$, meningkat tahun 2012 sebesar 20.257 ton $\mathrm{ha}^{-1}$. Meningkatnya konsumsi akan buah tomat menuntut kualitas yang semakin baik. Peningkatan kualitas tersebut dapat diperoleh bila menggunakan benih bermutu.

Benih yang bermutu akan menghasilkan produksi yang maksimal dan produk berkualitas. Mutu benih meliputi mutu fisik, genetik, dan fisiologi. Mutu fisik benih yang tinggi adalah benih yang bersih dari campuran kotoran seperti pasir, tanah, tangkai atau daun kering, bersih dari benih mati dan benih abnormal fisik, benih kosong. Benih bermutu fisik tinggi menunjukkan keseragaman dalam bentuk, ukuran, warna, dan berat per jumlah atau volume. Mutu genetik benih ditunjukkan dengan sifat genetik yang seragam. Mutu benih secara fisiologi adalah mutu yang diukur dari kemampuan benih yang dapat berproduksi normal pada kondisi yang normal pula (Sadjad, 1993). Mutu fisiologi benih yang menurun menyebabkan proses kemunduran benih. Hal ini dapat berpengaruh pada kemampuannya untuk berkecambah setelah mengalami penyimpanan.

Untuk mengetahui viabilitas suatu benih dapat dilakukan dengan beberapa cara, salah satunya dengan pengusangan cepat (accelerated aging). Metode pengusangan fisik merupakan metode yang paling mudah dan menyerupai kondisi alami saat di penyimpanan. Metode ini memberikan kondisi lingkungan yang suboptimum yang dapat menyebabkan kemunduran benih dalam penyimpanan yang sesuai kondisi sebenarnya (Mugnisjah, Setiawan, Suwarto, dan Santiwa, 1994). Metode ini pertama kali dilakukan oleh Delouche tahu 1971 menggunakan suhu $41^{\circ} \mathrm{C}$ dan $\mathrm{RH}$ $100 \%$ selama empat hari (Copeland dan McDonald, 2001).

Suhu yang rendah lebih baik dibandingkan suhu yang tinggi dalam penyimpanan benih karena suhu rendah dapat memperlambat penurunan viabilitas benih. Lama penderaan menjadikan kemunduran benih terus berlangsung, semakin lama benih didera semakin menurunkan viabilitas benih. Dengan meningkatnya suhu dan semakin lama penderaan terhadap benih tersebut maka umur penyimpanan menjadi lebih cepat dan viabilitas benih semakin menurun.

Penderaan menggunakan suhu 39 dan $41^{\circ} \mathrm{C}$ dengan kelembaban $100 \%$ merupakan factor yang dapat mempercepat kemunduran benih tomat karena dapat mempercepat respirasi dan metabolisme dalam benih. Semakin tinggi suhu dan semakin lama waktu penderaan akan semakin menurunkan viabilitas benih tomat. Selama penderaan benih akan menyerap kadar air dari kondisi yang lembab dan suhu yang tinggi. Hal ini yang menyebabkan cepatnya penuaan benih. Pada benih sesame yang didera pada suhu 42 dan $43^{\circ} \mathrm{C}$ masih 
menghasilkan perkecambahan rata-rata yang tinggi (Thant et al., 2010).

Penelitian ini bertujuan untuk mengetahui tingkat suhu deraan dan lama penderaan yang dapat menurunkan viabilitas benih tomat.

\section{BAHAN DAN METODE}

Penelitian dilaksanakan di laboratorium Benih dan Pemuliaan Tanaman, Fakultas Pertanian, Universitas Lampung pada Juni-Agustus 2012. Bahan-bahan yang digunakan adalah benih tomat varietas Oval yang dipanen pada Mei 2012 dan air. Alat-alat yang digunakan adalah dua inkubator, gelas plastik, pinset, kertas merang, sarangan kawat, kain strimin, alumunium foil, cawan petri, label, germinator, dan alat tulis.

Penelitian ini merupakan perlakuan faktorial 2x6 dalam rancangan kelompok teracak sempurna dengan 3 kali ulangan. Faktor pertama adalah dua taraf suhu, yaitu: $39\left(\mathrm{~S}_{1}\right)$ dan $41^{\circ} \mathrm{C}\left(\mathrm{S}_{2}\right)$. Faktor kedua adalah lama deraan yang terdiri atas 6 taraf, yaitu $0\left(\mathrm{~L}_{0}\right), 24\left(\mathrm{~L}_{1}\right), 48$ $\left(\mathrm{L}_{2}\right), 72\left(\mathrm{~L}_{3}\right), 96\left(\mathrm{~L}_{4}\right), 120\left(\mathrm{~L}_{5}\right)$ jam. Alat yang digunakan untuk penderaan benih secara fisik berupa gelas minum plastik dengan volume $240 \mathrm{ml}$. Gelas plastik tersebut diisi dengan air pada dasar gelas $\pm 80 \mathrm{ml}$, lalu diatas air diletakkan sarangan kawat dengan diameter $9 \mathrm{~cm}$, disesuaikan dengan ukuran gelas. Diatas sarangan kawat tersebut diletakkan kain strimin untuk benih tomat yang berukuran kecil, benih tomat diletakkan sebanyak 100 benih, gelas ditutup menggunakan alumunium foil dengan rapat dan diberi label pada gelas sesuai dengan perlakuannya. Gelas dimasukkan dalam dua inkubator yang telah diatur masing-masing pada suhu $39^{\circ}$ dan $41^{\circ} \mathrm{C}$, sesuai dengan perlakuan lama penderaan. Benih kemudian dikecambahkan dengan metode uji diatas kertas dalam satu kertas merang diisi 50 butir benih. Variabel yang diamati yaitu: kecepatan perkecambahan, kecambah normal total, kecambah abnormal, kecambah normal kuat, bobot kering kecambah normal, panjang hipokotil, panjang akar primer, benih mati. Kehomogenitasa ragam antarperlakuan dilihat dengan uji Bartlett. Kemenambahan data dengan uji Tuckey. Data dianalisis ragam dan uji lanjut menggunakan uji BNT pada taraf $5 \%$.

\section{HASIL DAN PEMBAHASAN}

Suhu 39 dan $41^{\circ} \mathrm{C}$ dengan kelembaban $100 \%$ telah menunjukkan terjadi penurunan viabilitas benih tomat varietas Oval selama $120 \mathrm{jam}$. Hasil rekapitulasi analisis ragam pengaruh suhu dan lama penderaan pada viabilitas benih tomat dapat dilihat pada Tabel 1. Hasil penelitian (Tabel 1) menunjukkan bahwa perlakuan suhu nyata ditunjukkan oleh variabel pengamatan panjang akar primer dan bobot kering kecambah normal. Perlakuan lama penderaan terlihat secara nyata pada semua variabel pengamatan kecuali pada variabel kecambah normal lemah. Pengaruh interaksi sangat nyata ditunjukkan oleh variabel pengamatan panjang akar primer, kecambah normal kuat, dan bobot kering kecambah normal.

Hasil penelitian (Tabel 2) menunjukkan perlakuan suhu menghasilkan pengaruh yang tidak berbeda pada beberapa variabel pengamatan. Hal ini mungkin disebabkan karena perbandingan antara kedua suhu yang tidak terlalu jauh yang menyebabkan tidak berbeda dalam

Tabel 1. Rekapitulasi hasil analisis ragam pengaruh suhu dan lama penderaan terhadap viabilitas tomat varietas opal pada variabel yang diamati

\begin{tabular}{lccc}
\hline & \multicolumn{3}{c}{ Perlakuan } \\
\cline { 2 - 4 } Variabel pengamatan & Suhu $\left({ }^{\circ} \mathrm{C}\right)$ & $\begin{array}{c}\text { Lama penderaan } \\
\text { (jam) }\end{array}$ & $\begin{array}{c}\text { Interaksi suhu dan } \\
\text { lama penderaan }\end{array}$ \\
\hline Kecepatan perkecambahan (KP) $(\% /$ hari) & tn & $*$ & tn \\
Kecambah normal total (KNT) $(\%)$ & tn & $*$ & tn \\
Kecambah normal kuat (KNK) $(\%)$ & tn & $*$ & $*$ \\
Kecambah normal lemah (KNL) $(\%)$ & tn & tn & tn \\
Kecambah abnormal (KAN) $(\%)$ & tn & $*$ & tn \\
Benih mati (BM) $(\%)$ & tn & $*$ & tn \\
Panjang hipokotil (PH) (cm) & tn & $*$ & $*$ \\
Panjang akar primer (PAP) $(\mathrm{cm})$ & $*$ & $*$ & $*$ \\
Bobot kering kecambah normal $(\mathrm{BKKN})(\mathrm{mg})$ & $*$ & $*$ & tn \\
\hline
\end{tabular}

Keterangan: $\mathrm{tn}=$ Tidak nyata dan $*=$ Nyata pada $\alpha=0,05$. 
menurunkan viabilitas benih. Namun pengaruh tersebut dapat terlihat pada variabel pengamatan panjang akar primer dan bobot kering kecambah normal.

Hasil penelitian (Tabel 3) menunjukkan bahwa penurunan kecepatan perkecambahan terlihat mulai dari lama penderaan 24 jam, semakin menurun pada 48 jam namun tidak berbeda sampai 120 jam. Pada kecambah normal total dan panjang hipokotil terjadi penurunan mulai dari lama penderaan 24 jam, namun tidak berbeda sampai 120 jam. Pada kecambah abnormal lama penderaan 24 jam dan 120 jam berbeda pada lama penderaan 0 dan 72 jam, namun keduanya tidak berbeda pada lama penderaan 48 dan 96 jam. Pada benih mati terjadi peningkatan persentase pada lama penderaan 72 jam. Penurunan kecambah abnormal ini diikuti oleh peningkatan persen benih mati. Lama penderaan pada suhu yang berbeda pada benih tomat varietas Oval menunjukkan pengaruhnya dalam menurunkan kecepatan perkecambahan, kecambah normal total, kecambah abnormal, benih mati, dan panjang hipokotil.
Pada variabel kecepatan perkecambahan, semakin lama waktu penderaan maka kecepatan perkecambahan semakin menurun. Hal yang sama juga terjadi pada kecambah normal total dan panjang hipokotil. Penurunan kecambah normal total dan panjang hipokotil ini meningkatkan persen kecambah abnormal dan benih mati, namun dua variabel tersebut menunjukkan nilai pengamatan yang tidak konsisten. Hal ini menunjukkan bahwa kecambah abnormal dan benih mati tidak efektif untuk memperlihatkan penurunan viabilitas benih tomat varietas Oval yang disebabkan oleh lama penderaan pada suhu tertentu.

Hasil penelitian (Tabel 4) menunjukkan bahwa terdapat perbedaan yang nyata pada penurunan kecambah normal kuat. Pada suhu $39^{\circ} \mathrm{C}$ penurunan kecambah normal kuat terjadi pada lama penderaan 24 jam. Pada suhu $41^{\circ} \mathrm{C}$ pada lama penderaan 24 jam. Pada lama penderaan 72 jam dapat menurunkan kecambah normal kuat dengan suhu $41^{\circ} \mathrm{C}$. Hasil ini serupa dengan penelitian Torres dan Filho (2003), yang

Tabel 2. Pengaruh suhu terhadap viabilitas benih tomat varietas Oval

\begin{tabular}{ccccccc}
\hline \multirow{2}{*}{ Suhu $\left({ }^{\circ} \mathrm{C}\right)$} & \begin{tabular}{c} 
Variabel pengamatan \\
Kecepatan \\
\cline { 2 - 7 }
\end{tabular} & $\begin{array}{c}\text { Kecambah } \\
\text { normal total } \\
(\%)\end{array}$ & $\begin{array}{c}\text { Kecambah } \\
\text { normal lemah } \\
(\%)\end{array}$ & $\begin{array}{c}\text { Kecambah } \\
\text { abnormal } \\
(\%)\end{array}$ & $\begin{array}{c}\text { Benih } \\
\text { mati } \\
(\%)\end{array}$ & $\begin{array}{c}\text { Panjang } \\
\text { hipokotil } \\
(\mathrm{cm})\end{array}$ \\
\hline 39 & $10,62 \mathrm{a}$ & $68,11 \mathrm{a}$ & $1,78 \mathrm{a}$ & $7,00 \mathrm{a}$ & $21,44 \mathrm{a}$ & $5,45 \mathrm{a}$ \\
41 & $10,03 \mathrm{a}$ & $64,89 \mathrm{a}$ & $1,88 \mathrm{a}$ & $6,83 \mathrm{a}$ & $22,00 \mathrm{a}$ & $5,47 \mathrm{a}$ \\
\hline BNT & 1,34 & 7,91 & 0,17 & 2,27 & 2,53 & 0,16 \\
\hline
\end{tabular}

Keterangan: Nilai tengah yang diikuti huruf yang sama tidak berbeda nyata berdasarkan Uji BNT pada $\alpha=0,05$.

Tabel3. Pengaruh lama penderaan terhadap viabilitas benih tomat varietas Oval

\begin{tabular}{cccccc}
\hline \multirow{2}{*}{$\begin{array}{c}\text { Lama } \\
\text { penderaan (jam) }\end{array}$} & $\begin{array}{c}\text { Kecepatan } \\
\text { perkecambahan } \\
(\%)\end{array}$ & $\begin{array}{c}\text { Kecambah } \\
\text { normal total } \\
(\%)\end{array}$ & $\begin{array}{c}\text { Kecambah } \\
\text { abnormal } \\
(\%)\end{array}$ & $\begin{array}{c}\text { Benih mati } \\
(\%)\end{array}$ & $\begin{array}{c}\text { Panjang } \\
\text { Hipokotil } \\
(\mathrm{cm})\end{array}$ \\
\hline 0 & $15,11 \mathrm{a}$ & $87,33 \mathrm{a}$ & $4,00 \mathrm{~b}$ & $8,67 \mathrm{~d}$ & $6,08 \mathrm{a}$ \\
24 & $11,37 \mathrm{~b}$ & $71,67 \mathrm{~b}$ & $9,67 \mathrm{a}$ & $17,33 \mathrm{c}$ & $5,37 \mathrm{~b}$ \\
48 & $8,97 \mathrm{c}$ & $62,00 \mathrm{~b}$ & $7,00 \mathrm{ab}$ & $20,00 \mathrm{c}$ & $5,35 \mathrm{~b}$ \\
72 & $8,87 \mathrm{c}$ & $60,33 \mathrm{~b}$ & $5,00 \mathrm{~b}$ & $32,33 \mathrm{a}$ & $5,35 \mathrm{~b}$ \\
96 & $8,69 \mathrm{c}$ & $58,67 \mathrm{~b}$ & $6,83 \mathrm{ab}$ & $26,67 \mathrm{~b}$ & $5,21 \mathrm{~b}$ \\
120 & $8,91 \mathrm{c}$ & $59,00 \mathrm{~b}$ & $9,00 \mathrm{a}$ & $25,33 \mathrm{~b}$ & $5,39 \mathrm{~b}$ \\
\hline BNT & 2,32 & 13,69 & 3,92 & 4,39 & 0,28 \\
\hline
\end{tabular}

Keterangan: Nilai tengah yang diikuti huruf yang sama tidak berbeda berdasarkan Uji BNT pada $\alpha=0,05$. 
menunjukkan penderaan fisik benih melon menggunakan suhu $38^{\circ} \mathrm{C}$ dan $41^{\circ} \mathrm{C}$ sensitif menurnkan perkecambahan pada lama penderaan 72 dan 96 jam. Selanjutnya, hasil penelitian Navamaniraj, Srimathi, Ponnusawamy, dan Sudaghar (2008) menunjukkan bahwa pada benih Bixa orellana yang diskarifikasi dan didera pada suhu $41^{\circ} \mathrm{C}$ menurunkan perkecambahan 50-5\% dalam kurun waktu 0-20 hari.

Hasil penelitian (Tabel 5) menunjukkan bahwa perlakuan suhu $39^{\circ} \mathrm{C}$ dan $41^{\circ} \mathrm{C}$ dapat menurunkan panjang akar primer pada lama penderaan 24 jam. Pada lama penderaan 48 jam dapat menurunkan panjang akar primer dengan suhu $39^{\circ} \mathrm{C}$, sedangkan pada lama penderaan 96 dan 120 dapat menurunkan panjang akar primer dengan suhu $41{ }^{\circ} \mathrm{C}$. Hal ini berbeda dengan hasil penelitian Sukarman, Rusmin, dan Hasanah (1996), bahwa pada benih jambu mente, panjang akar primer terendah dihasilkan pada benih tanpa didera.

Hasil penelitian (Tabel 6) menunjukkan bahwa pada suhu $39^{\circ} \mathrm{C}$ dan $41^{\circ} \mathrm{C}$ penurunan bobot kering kecambah normal sudah terlihat pada lama penderaan 24 jam. Suhu $39^{\circ} \mathrm{C}$ dengan lama penderaan 0 jam menghasilkan bobot kering kecambah normal tertinggi, dan terendah pada lama penderaan $120 \mathrm{jam}$. Pada suhu $41^{\circ} \mathrm{C}$ dengan lama penderaan 0 jam mengasilkan bobot kering kecambah normal tertinggi, dan terendah pada lama penderaan 72 jam. Pada lama penderaan 48, 72 dan 96 dapat menurunkan bobot kering kecambah normal dengan suhu $41^{\circ} \mathrm{C}$. Penurunan bobot kering menunjukkan semakin banyak cadangan makanan yang digunakan benih tomat selama penderaan dalam inkubator. Serupa dengan penelitian Sukarman, dkk. (1996), bahwa bobot kering kecambah mente menurun pada lama penderaan satu hari pada suhu perkecambahan $30-37^{\circ} \mathrm{C}$. Stan (1997) menyebutkan bahwa peningkatan kelembaban dan temperatur pada suatu lot benih disebabkan oleh proses respirasi yang menyebabkan hilangnya kapasitas perkecambahan dan penurunan vigor benih.

Tabel 4. Pengaruh interaksi suhu dan lama penderaan terhadap kecambah normal kuat (\%)

\begin{tabular}{ccccccc}
\hline & \multicolumn{7}{c}{ Kecambah normal kuat $(\%)$} \\
\cline { 2 - 7 } Suhu $\left({ }^{\circ} \mathrm{C}\right)$ & \multicolumn{7}{c}{ Lama penderaan (jam) } \\
\cline { 2 - 7 } & 0 & 24 & 48 & 72 & 96 & 120 \\
\cline { 2 - 7 } & $73,33 \mathrm{a}$ & $54,67 \mathrm{bc}$ & $49,33 \mathrm{bc}$ & $56,67 \mathrm{~b}$ & $50,00 \mathrm{bc}$ & $46,67 \mathrm{c}$ \\
39 & $\mathrm{~A}$ & $\mathrm{~A}$ & $\mathrm{~A}$ & $\mathrm{~A}$ & $\mathrm{~A}$ & $\mathrm{~A}$ \\
& $73,33 \mathrm{a}$ & $63,33 \mathrm{~b}$ & $56,67 \mathrm{bc}$ & $27,33 \mathrm{e}$ & $44,67 \mathrm{~d}$ & $49,33 \mathrm{~cd}$ \\
41 & $\mathrm{~A}$ & $\mathrm{~A}$ & $\mathrm{~A}$ & $\mathrm{~A}$ & $\mathrm{~A}$ & $\mathrm{~A}$ \\
\hline BNT & \multicolumn{7}{c}{9,03}
\end{tabular}

Keterangan: Nilai tengah yang diikuti oleh huruf kecil (dalam baris) atau huruf kapital (dalam kolom) yang yang sama menunjukkan tidak berbeda nyata berdasarkan Uji BNT pada $\alpha=0,05$.

Tabel 5. Pengaruh interaksi suhu dan lama penderaan terhadap panjang akar primer $(\mathrm{cm})$

\begin{tabular}{|c|c|c|c|c|c|c|}
\hline \multirow{3}{*}{ Suhu $\left({ }^{\circ} \mathrm{C}\right)$} & \multicolumn{6}{|c|}{ Panjang akar primer $(\mathrm{cm})$} \\
\hline & \multicolumn{6}{|c|}{ Lama penderaan (jam) } \\
\hline & 0 & 24 & 48 & 72 & 96 & 120 \\
\hline \multirow{3}{*}{39} & $6,33 \mathrm{a}$ & $5,91 \mathrm{~b}$ & $5,63 \mathrm{c}$ & $5,65 \mathrm{c}$ & $5,71 \mathrm{c}$ & $5,44 \mathrm{~d}$ \\
\hline & A & A & $\mathrm{B}$ & A & A & A \\
\hline & $6,33 \mathrm{a}$ & $5,87 \mathrm{~b}$ & $5,81 \mathrm{~b}$ & $5,63 \mathrm{c}$ & $5,38 \mathrm{~d}$ & $5,09 \mathrm{e}$ \\
\hline 41 & A & A & A & A & B & B \\
\hline
\end{tabular}

Keterangan: Nilai tengah yang diikuti oleh huruf kecil (dalam baris) atau huruf kapital (dalam kolom) yang yang sama menunjukkan tidak berbeda nyata berdasarkan Uji BNT pada $\alpha=0,05$. 
Tabel 6. Pengaruh interaksi suhu dan lama penderaan terhadap bobot kering kecambah normal (mg)

\begin{tabular}{ccccccc}
\hline & \multicolumn{7}{c}{ Bobot kering kecambah normal $(\mathrm{mg})$} \\
\cline { 2 - 7 } Suhu $\left({ }^{\circ} \mathrm{C}\right)$ & \multicolumn{7}{c}{ Lama penderaan (jam) } \\
\cline { 2 - 7 } & 0 & 24 & 48 & 72 & 96 & 120 \\
\cline { 2 - 7 } & $1,87 \mathrm{a}$ & $1,67 \mathrm{~b}$ & $1,64 \mathrm{~b}$ & $1,38 \mathrm{c}$ & $1,36 \mathrm{c}$ & $1,29 \mathrm{~d}$ \\
39 & $\mathrm{~A}$ & $\mathrm{~A}$ & $\mathrm{~A}$ & $\mathrm{~A}$ & $\mathrm{~A}$ & $\mathrm{~A}$ \\
& $1,87 \mathrm{a}$ & $1,700 \mathrm{~b}$ & $1,42 \mathrm{c}$ & $1,26 \mathrm{e}$ & $1,23 \mathrm{e}$ & $1,33 \mathrm{~d}$ \\
41 & $\mathrm{~A}$ & $\mathrm{~A}$ & $\mathrm{~B}$ & $\mathrm{~B}$ & $\mathrm{~B}$ & $\mathrm{~A}$ \\
\hline BNT & \multicolumn{7}{c}{0,05} \\
\hline
\end{tabular}

Keterangan: Nilai tengah yang diikuti oleh huruf kecil (dalam baris) atau huruf kapital (dalam kolom) yang yang sama menunjukkan tidak berbeda nyata berdasarkan Uji BNT pada $\alpha=0,05$.

Suhu 39 dan $41^{\circ} \mathrm{C}$ tidak berbeda dalam menurunkan viabiitas benih tomat yang ditunjukkan oleh variabel kecepatan perkecambahan, kecambah normal total, kecambah normal lemah, kecambah abnormal, benihi mati, dan panjang hipokoti. Lama penderaan menurunkan viabilitas benih tomat pada 24 jam bila dibandingkan dengan benih toamat tanpa didera, hal ini ditujukkan oleh variabel kecepatan perkecambahan, kecambah normal total, panjang hipkotil, kecambah abnormal, dan benih mati. Jianhua dan McDonald (1996), menyebutkan bahwa benih berukuran kecil akan mengalami sensitifitas tinggi sehingga kemunduran lebih cepat pada metode pengusanan dipercepat. Kombinasi suhu dan lama penderaan yang efektif untuk menurunkan viabilitas benih tomat varietas Oval adalah suhu $39^{\circ} \mathrm{C}$ dengan lama penderaan 24 jam dan suhu $41^{\circ} \mathrm{C}$ dengan lama penderaan 24 jam yang ditunjukkan oleh variabel kecambah normal kuat, panjang akar primer, dan bobot kering kecambah normal. Penurunan viabilitas benih tomat ini didukung juga oleh pengaruh utama lama penderaan pada 24 jam yang sudah menurunkan kecepatan perkecambahan, kecambah normal total, dan panjang hipokotil. Dengan demikian benih tomat varietas Oval yang telah mengalami masa penyimpanan dengan suhu 39 dan $41^{\circ} \mathrm{C}$ tidak dapat mempertahankan viabilitasnya selama 24 jam sebanyak $10 \%$ bila dibandingkan dengan benih tanpa didera.

\section{KESIMPULAN}

Berdasarkan penelitian yang telah dilakukan, maka diperoleh kesimpulan bahwa penderaan menggunakan suhu $39^{\circ} \mathrm{C}$ dengan lama penderaan 24 jam atau suhu $41^{\circ} \mathrm{C}$ dengan lama penderaan 24 jam sudah menurunkan viabilitas benih tomat yang ditunjukkan oleh variabel kecambah normal kuat, panjang akar primer, dan bobot kering kecambah normal.

\section{PUSTAKA ACUAN}

Badan Pusat Statistik. 2012. Data Produksi Tomat Tahun 1997-2011. http://www.bps.go.id/ tab_sub/view.php?kat=3\&tabel $=1 \&$ daftar $=$ 1\&id_subyek=55\&notab=27. 21 Maret 2012.

Copeland L. O. dan M. B. McDonald. 2001. Seed Science and Technology. Kluwer Academic Publishers. America.

Jianhua, Z. dan M. B. McDonald. 1996. The Saturated Salt Accelerated Aging Test for Small- Seeded Crops. Seed Sci. Technol. 25(1): 123-131.

Mugnisjah, W.Q., A. Setiawan, Suwarto, dan C. Santiwa. 1994. Panduan Praktikum dan Penelitian Bidang Ilmu dan Teknologi Benih. PT. Raja Grafindo Persada. Jakarta.

Navamaniraj, K. N., P. Srimathi, A. S. Ponnuswamy, and R. J. Sudhagar. 2008. Performance of Scarified and non Scarified Seed of Bixa Orellana to Accelerated Aging Test for the Prediction of Seed Storability. Research J. of Agric. And Biol. Sci. 4(5): 591-594.

Sadjad, S. 1993. Dari Benih Kepada Benih. PT. Gramedia Widiasarana Indonesia. Jakarta.

Stan, O. 1997. The Test of Accelerated Ageing to Establish the vigour Potential in Maize and Sunflower Hybrid Seed. Research Institute for Cereals and Industrial Crops. Romania. No. 7-8: 59-66.

Sukarman, D. Rusmin, dan M. Hasanah. 1996. Pengaruh Penderaan dan Suhu Perkecambahan terhadap Viabilitas Benih Jambu Mente. J. Littri. 1(6): 284-290. 
Thant, K. H., J. Duangpatra, dan J. Romkaew. 2010. Appropriate Temperature and Time for Accelerated Aging Vigor Test in Sesame (Sesanum indicum L.) Seed. J. Nat. Sci. 44: 1016.
Torres, S. B. dan A. M. Filho. 2003. Accelerated Aging of Melon Seed. Scientia Agricola. 60(1): 7782. 